\title{
SEISMIC DAMAGE SCENARIOS INDUCED BY SITE EFFECTS OF MASONRY CLUSTERED BUILDINGS: A SOUTH ITALY CASE STUDY
}

\author{
A. FORMISANO ${ }^{1 *}$, N. CHIEFFO ${ }^{2}$ \\ ${ }^{1}$ Department of Structures for Engineering and Architecture \\ School of Polytechnic and Basic Sciences, University of Naples "Federico II" \\ P.le V. Tecchio, 80125 Naples, Italy \\ e-mail: antoform@unina.it (*corresponding author) \\ ${ }^{2}$ Faculty of Architecture and Urbanism \\ Politehnica University of Timişoara \\ Traian Lalescu Street 2/A, 300223 Timişoara, Romania \\ email: nicola.chieffo@student.upt.ro
}

Keywords: Site-Effects, Vulnerability Assessment, Masonry Aggregates, Damage Scenarios, Vulnerability Curves

\begin{abstract}
The present research aims to investigate the influence of site amplification on the seismic vulnerability of the historical centre of the municipality of Baranello in the Molise Region of Italy. Structural and typological characterization of the investigated area has been done according to the EMS-98 scale. The vulnerability assessment of the historical buildings located there has been carried out through an appropriate survey form in order to identify the buildings most susceptible at seismic damage. Furthermore, according to the AeDES form implemented by the Italian Civil Protection Department, the calibration of the typological vulnerability curves of the built-up area has been done based on the seismic motions recorded after the 2002 Molise earthquake. Finally, the local amplification factor, which negatively influences the severity of the seismic damage on the structures, has been taken into account according to the time-domain method. To this purpose, a refined and simplified approach to foresee the expected damage of the inspected urban sector has been proposed, so to use more appropriately the achieved results for reliable seismic risk mitigation plans.
\end{abstract}

\section{INTRODUCTION}

The seismic vulnerability of a given built area indicates the expected amount of damage triggered by an earthquake of a specific magnitude. The recent tragic earthquakes occurred in Italy during the last decades are a living testimony of the bad seismic behaviour of the historical centres of many municipalities [1]. Generally, the occurrence of near-field earthquakes has required to adopt methods of predicting the expected damage taking into account the influence of the local seismic response on inhabited areas. This is due to a series of hazardous factors, such as the age of buildings, the poor quality of materials and the insufficient maintenance of constructions, which lead towards the high seismic vulnerability of several built-up areas. 
Focusing on the urban scale, rapid urbanization has dramatically increased the vulnerability and risk of urban dwellers in densely populated areas. The available strategies for seismic vulnerability assessment usually have as starting point the compilation appropriate survey forms, based on several parameters, i.e. the seismic-resistant system type to lateral loading, the structural regularity and maintenance conditions and the presence of existing damages, to collect information on historical centre buildings. The application of these survey forms allows to fully understand the various structural types located within heterogeneous urban centres [2, 3].

Nowadays, the evaluation of geological effects has been taken into consideration in the framework of risk assessment in order to have a better and correct forecast of the expected damage. In this framework, it is recognised that soil layers amplify or reduce the seismic waves on the crustal surface. Site effects are, thus, dangerous when the amplification of seismic waves in surface geological layers occurs.

Based on these considerations, the municipality of Baranello, in the province of Campobasso, has been selected as a case study to evaluate the possible damages under seismic events considering site effects. The proposed work aims to evaluate the local amplification effects considering the time domain of a 1D half-space ground model. The main goal of this work is to investigate the influence of soil amplification on the seismic behaviour of typical masonry aggregates with the final target to plot the damage scenarios expected under different earthquake moment magnitudes and site-source distances.

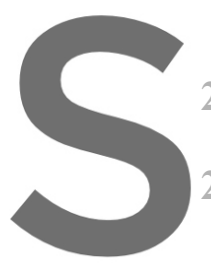

2 THE MUNICIPALITY O

2.1 Historical background
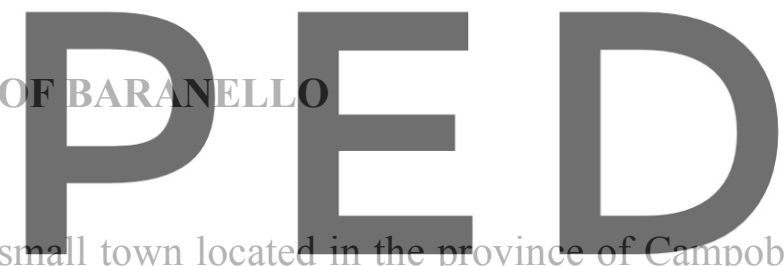

Baranello (Figure 1) is a sinall town locat d
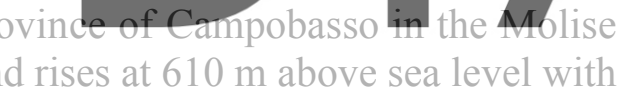

Region of Italy. The municipality has 2759 inhabitants and rises at $610 \mathrm{~m}$ above sea level with

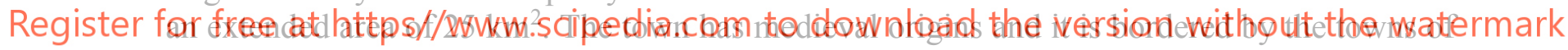
Busso, Colle d'Anchise, Spinete and Vinchiaturo.

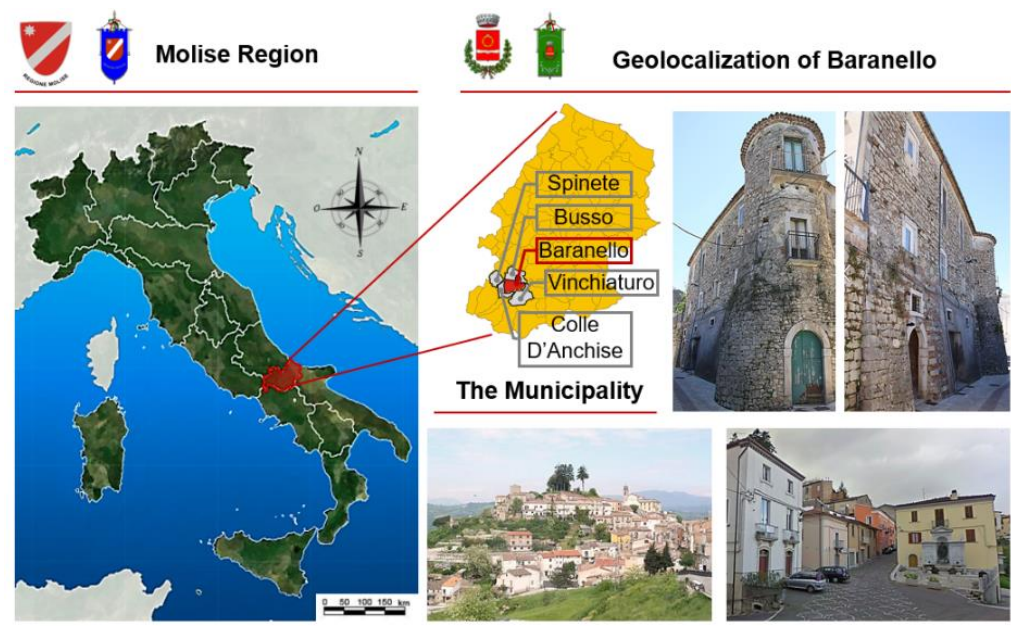

Figure 1: Geographical localization of the municipality of Baranello. 
There are limited historical news about the evolution of the centre during time. The village was mentioned for the first time in the fourteenth century as a possession of Capece Galeota's family dating back to Norman ages. Only in 1591 the feud was sold by the Carafa family, from which the Pope Paul IV descended, to the Marquis one and then to Angelo Barone. Nowadays, the territory has the characteristics of a mountain centre: narrow and steep streets that enlarge towards the area of new settlements. The urban centre is characterized by both houses preserving their original appearance, which are located around the church and along the main streets, and more modern buildings, that are placed in other districts belonging to the municipal territory.

\subsection{The 2002 Molise seismic event}

The Molise earthquake was a significant event, occurred on 2002 October $31^{\text {st }}$, having the epicentre localized in the province of Campobasso among the municipalities of San Giuliano di Puglia, Colletorto, Santa Croce di Magliano, Bonefro, Castellino del Biferno and Provvidenti. This seismic event, having magnitude $\mathrm{M}_{\mathrm{W}}=5.7$, was perceived in a large area of Central-Southern Italy, causing significant damage in a restricted area between Frentani, Sannio and Foggia (Figure 2).

The aftershocks (more than 1900 seismic events) showed a predominantly vertical seismogenic structure, having a depth between 10 and $25 \mathrm{~km}$, which was oriented in an eastwest direction and consisted of two main segments, each with a length of about $15 \mathrm{~km}$. Also, a

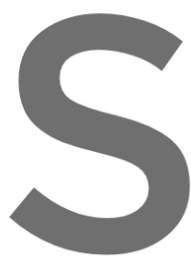
$10.5 \times 8.0 \mathrm{~km}^{2}$ fault plan October $31^{\text {st }}$ event $[4$
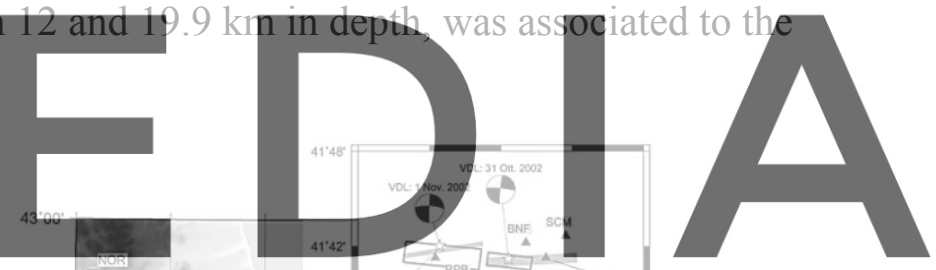

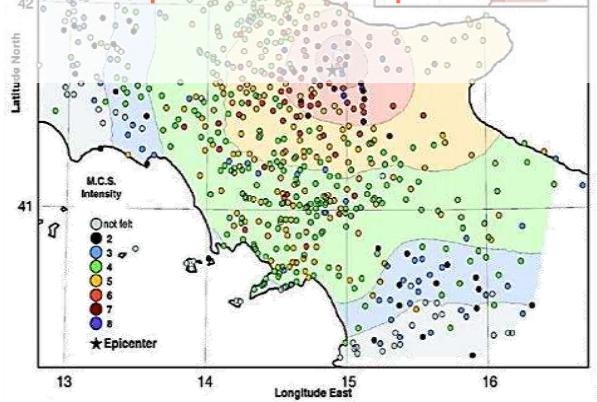

(a)

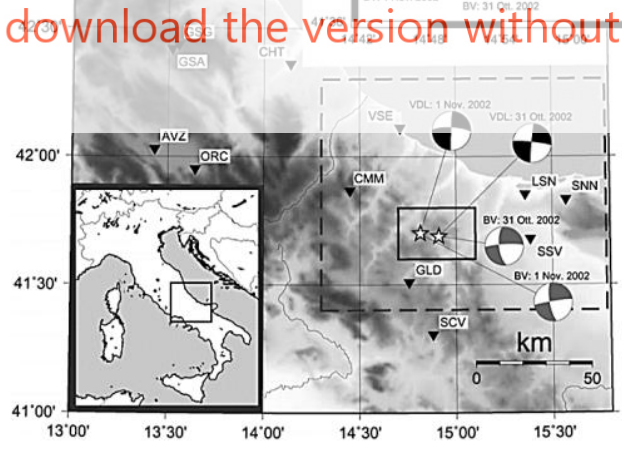

(b)

Figure 2: Distribution of earthquakes in the Molise Region area: (a) macroseismic intensities; (b) focal mechanisms of the fault model.

Figure 2a shows the macroseismic intensities occurred after the events previously mentioned. In the area near the epicentre, the maximum intensity recorded was VI according to the MCS scale. Moreover, Figure $2 b$ describes the surface projections and focal mechanisms of the fault model for the Molise earthquake. In particular, in the central panel the accelerometric 
stations, that recorded the mainshocks of the seismic sequence, have been marked with triangles, while dashed rectangle denotes the recording stations and the upper solid rectangle points out the seismogenic sources which generated the seismic event.

\section{TYPOLOGICAL AND STRUCTURAL DESCRIPTION OF THE BUILT-UP AREA}

\subsection{The CARTIS survey form}

The structural and typological characterization of the built-up is considered indispensable for the census of the buildings exposed at risk, which is a preliminary phase for their classification into typological classes.

The CARTIS form has been conceived by both the PLINIVS research centre of the University of Naples "Federico II" and the Italian Civil Protection Department in the framework of the ReLUIS 2014-2016 project "Development of a systematic methodology for the territorial scale exposure assessment based on the typological/structural characteristics of buildings" [5]. The CARTIS form has been herein used in order to detect the prevalent ordinary building typologies in municipal or sub-municipal territorial parts, called urban sectors, characterized by typological and structural homogeneity. In the historical centre of Baranello one unique compartment, labelled as C01 and composed of 300 buildings, has been considered (Figure 3).
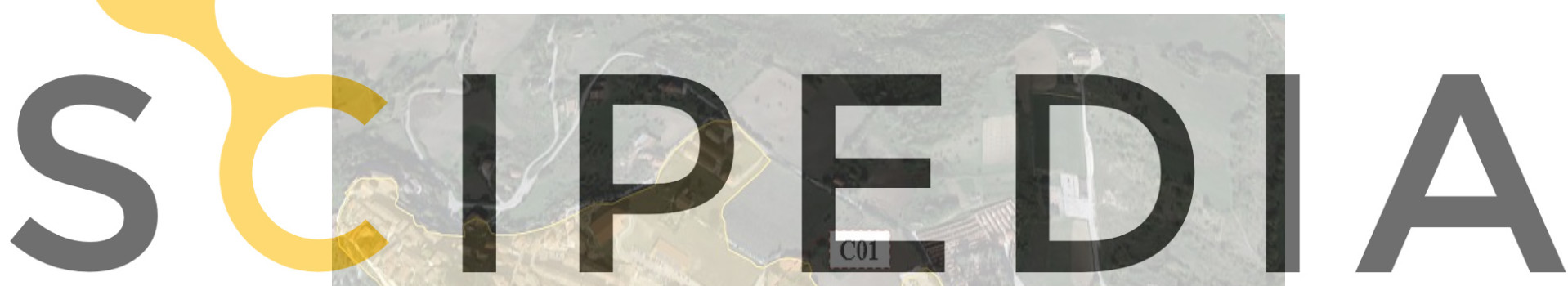

Register for free at https//www.scipedia.com to download the version without the watermark

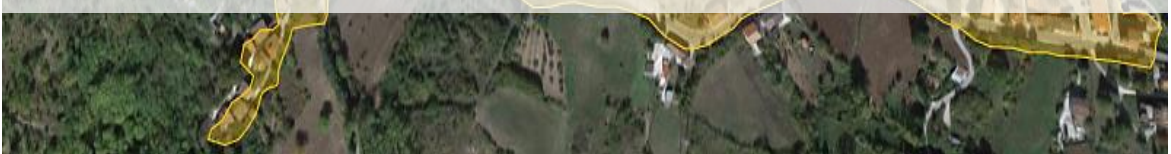

Figure 3: The C01 urban sector detected in the municipality of Baranello.

Most of the buildings have been built using rough-hewn stones assembled according to the technique of either sack or mixed walls, which in some cases do not respect the "rules of art" indispensable to guarantee a satisfactory behaviour of the masonry apparatus against seismic actions.

The houses characterising the historical centre are composed of walls with an average thickness of $0.65 \mathrm{~m}$ and an average inter-storey height of $3.50 \mathrm{~m}$.

Other than masonry vaults, horizontal structures are represented by timber or steel floors, which are also the main structure of coverages (Figure 4).

The data collected through the CARTIS form has allowed, through statistical elaborations, to provide indications on the constructive age, number of storeys, average surface and wall type 
of the sample of buildings surveyed within the municipality examined. The results obtained are summarized in the cumulative distributions reported in Figure 5.
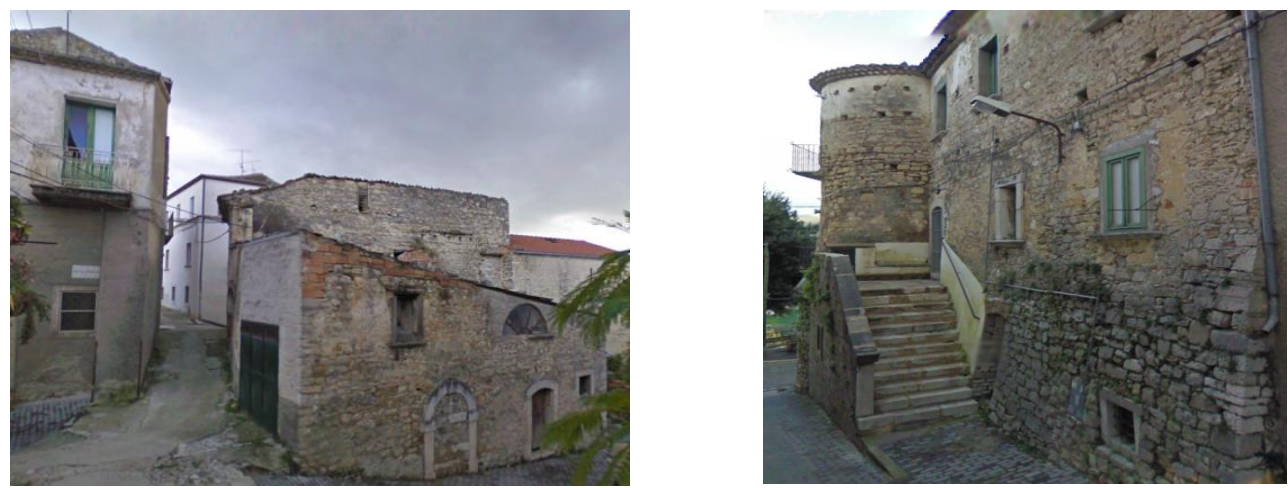

Figure 4: Street views of the prevalent building typologies inside the inspected area.
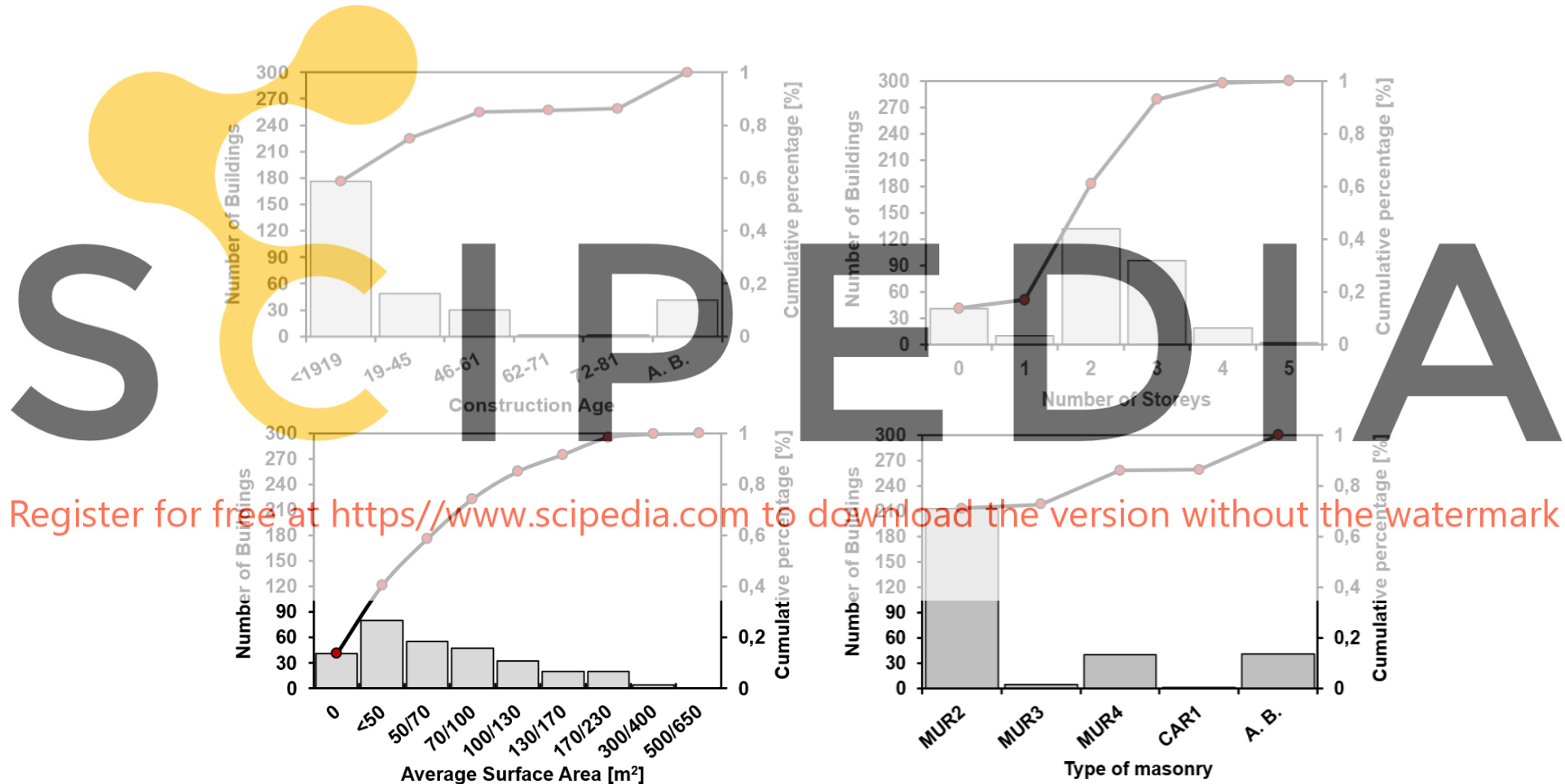

Figure 5: Preliminary characteristics of buildings surveyed in the municipality of Baranello.

From the data surveyed on the inspected buildings, the prevailing typological class is the MUR2 (rough-hewn stones) one, which has been detected in $73 \%$ of the cases ( 220 buildings). The other classes detected in the study area are the MUR3 (rough-hewn masonry stones or pseudo-regular stones, $2 \%$ of the building sample) and MUR4 (regular masonry with squared or brick stones, $13 \%$ of the building sample) ones, whereas $12 \%$ of the building sample are represented by unused constructions. 


\subsection{Large scale seismic vulnerability assessment}

A seismic vulnerability assessment at urban scale has been herein implemented in order to evaluate the propensity at damage of buildings placed in the municipality of Baranello. In this context, a vulnerability index-based method has been adopted. The proposed method has the peculiarity of investigating the seismic vulnerability of buildings grouped in compounds through a specific vulnerability form [6-9].

The used survey form, composed of 15 parameters, is appropriate for masonry building aggregates, since it takes into account the effects of mutual interaction among aggregated Structural Units (S.Us) under earthquakes.

Methodologically, the vulnerability index, Iv, for each S.U., is intended as the weighted sum of the class selected for each of the 15 parameters multiplied by the respective weight. Each of the estimated parameters are grouped into four vulnerability classes (A, B, C and D, from the best to the worst), characterised by a specific score (also with a negative sign in case of a vulnerability reduction), to which a correspondent weight, $W_{i}$, is assigned. The weight of parameters is variable from a minimum of 0.25 for the less important factors up to a maximum of 1.50 for the most important ones.

The compilation of the survey forms for the aggregated S.Us of Baranello has provided the distribution of the vulnerability indexes reported in Figure 6.
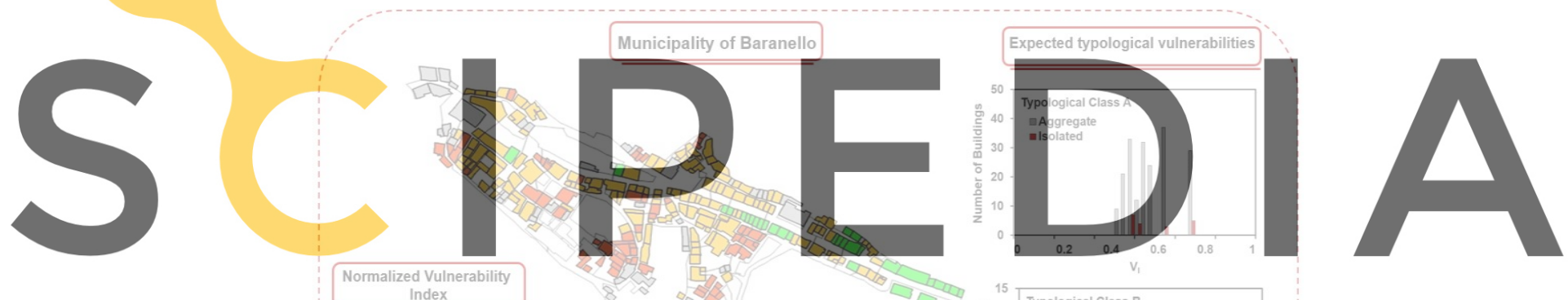

Register for free at https//Www.scipedia.com to download
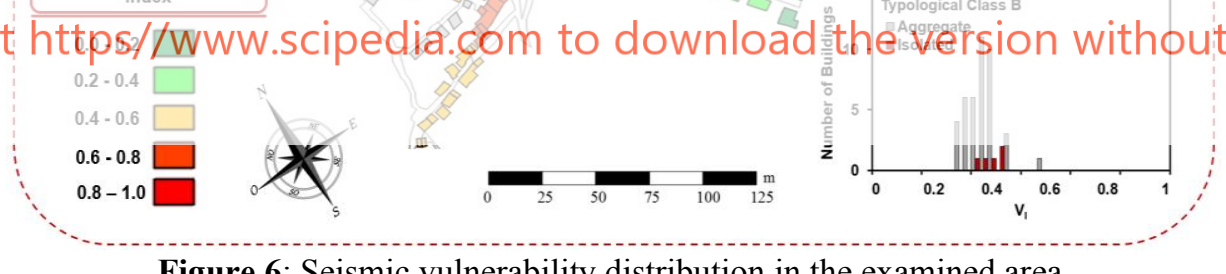

Figure 6: Seismic vulnerability distribution in the examined area.

\subsection{Seismic impact scenarios}

The prediction of the seismicity of a specific site can be evaluated by adopting appropriate seismic attenuation laws, which are empirical formulations calibrated on the statistical data (instrumental or macroseismic) derived from earthquakes occurred. Generally, these laws are based on simplified models in order to represent seismic propagation. In practice, an empirical relationship is established between the parameter representative of the motion, which can be given by the macroseismic intensity, and other factors, like the energy released at the source in terms of magnitude $\left(\mathrm{M}_{\mathrm{w}}\right)$ and the epicentre distance $(\mathrm{R})$. In the current research, the severity of the seismic effects has been analysed by predictive analyses using the Esteva and Harris' seismic attenuation law [10]. 
In detail, a deterministic approach has been used by selecting as reference earthquakes, according to the Parametric Catalogue of Italian Earthquakes (CPTI15) [11], three events of increasing moment magnitudes $(4,5$ and 6$)$ occurred in the past in the Molise region of Italy.

After these magnitudes have been selected, the selection of different epicentre distances, namely 5, 17 and $35 \mathrm{Km}$, has allowed to plot the expected damage scenarios.

Based on the attenuation law above mentioned, the macroseismic intensities have been correlated to the earthquake magnitudes and epicentre distances, leading towards the nine damage scenarios reported in Table 1.

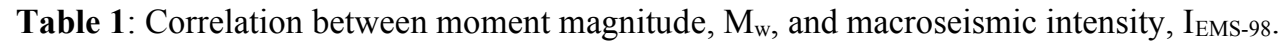

\begin{tabular}{cccc}
\hline \multirow{2}{*}{ Magnitude $\mathbf{M}_{\mathbf{w}}$} & \multicolumn{3}{c}{ Macroseismic Intensity $\mathbf{I}_{\text {EMS-98 }}$} \\
\cline { 2 - 4 } & $\mathrm{R}=5 \mathrm{~km}$ & $\mathrm{R}=17 \mathrm{~km}$ & $\mathrm{R}=35 \mathrm{~km}$ \\
\hline $\mathbf{4}$ & $\mathrm{X}$ & $\mathrm{VII}$ & $\mathrm{V}$ \\
\hline 5 & $\mathrm{XI}$ & VIII & VII \\
\hline 6 & $\mathrm{XII}$ & $\mathrm{X}$ & VIII
\end{tabular}

\section{Therefore, the damage scenarios achieved according to the Esteva and Harris' attenuation} law considering $\mathrm{R}=5 \mathrm{Km}$ have been plotted in Figure 7 to show the most dangerous seismic analysis case.
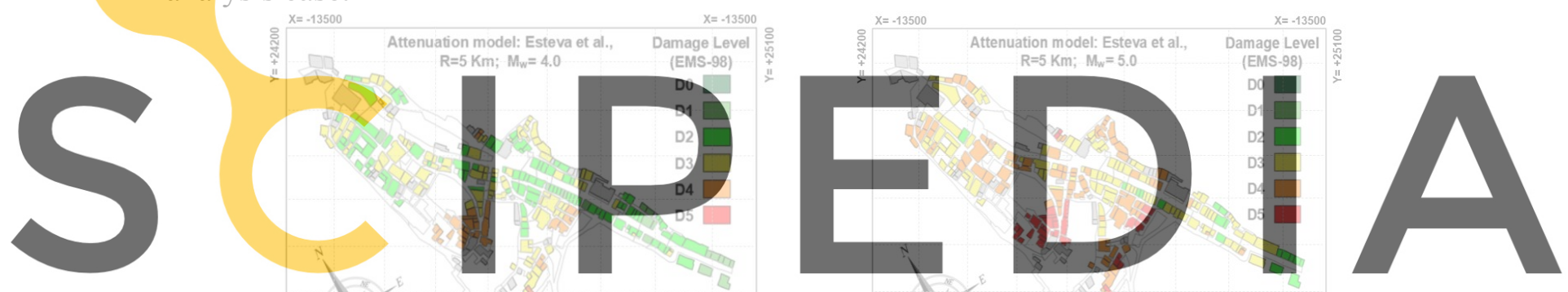

Register for free at https//www.scipedia.com to download the version without the watermark

(a)

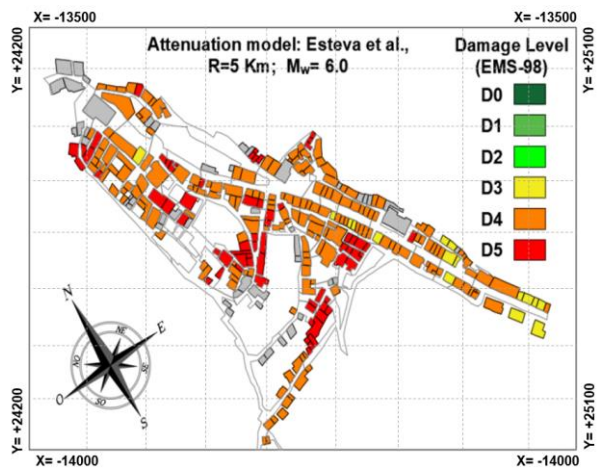

(b)

(c)

Figure 7: The impact damage scenarios for variable magnitudes and epicentre distance of $5 \mathrm{Km}$ in the investigated urban area.

Then, the correlation between the mean damage grade, $\mu_{\mathrm{D}}$, and the damage thresholds, $\mathrm{D}_{\mathrm{K}}$, 
have been developed according to the EMS-98 scale (Figure 8).

From the analysis results, it appears that for $\mathrm{M}_{\mathrm{w}}=4$ about $61 \%$ of the buildings suffer damage $\mathrm{D} 2$, while for $\mathrm{M}_{\mathrm{w}}=6$, damage thresholds D4 (near-collapse) and D5 (collapse) are attained in $68 \%$ and $25 \%$ of the cases, respectively. Contrary, when $\mathrm{M}_{\mathrm{w}}=5$, a more variable damage distribution is achieved.
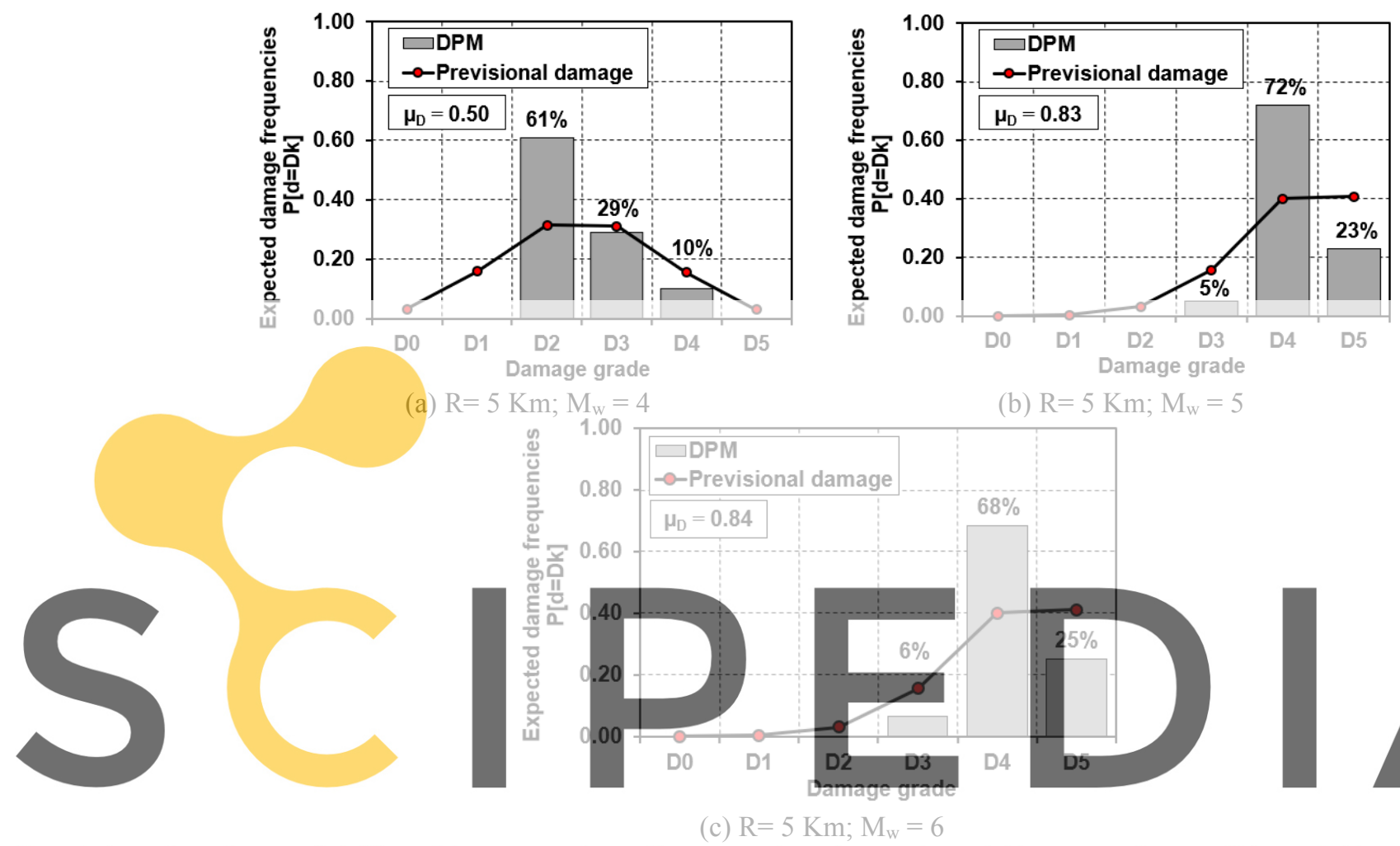

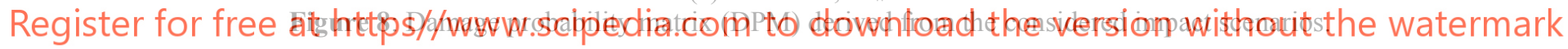

4 INELUENCE OF LOCAL SITE EFFECTS ON THE VULNERABHLTY ASSESSMENT

From the physical point of view, the local seismic response can be intended as a set of changes in amplitude, duration and frequency content that the seismic motion undergoes through the overlying layers of soil up to the surface. In other words, the ground layers can increase the amplitude of the seismic motion at some frequencies and reduce it for other ones.

The schematization of seismic motion can be represented in the domain of either time or frequencies. In particular, considering the time domain, the parameters most frequently used to describe the earthquake characteristics are the peak value of the acceleration, of the velocity, of the displacement, and the duration. Contrary, in the frequency domain, the seismic motion parameters are characterized by either the Fourier spectrum or the response spectrum.

The problem of geo-hazard effects has been already contemplated in [12] where, under a macroseismic approach and on the basis of macroelement numerical analysis on clustered buildings, the site effects were taken into account through a local amplification coefficient, $f_{P G A}$, defined as the ratio between the maximum recorded acceleration at the ground surface $\left(\mathrm{a}_{\max , \mathrm{s}}\right)$ 
and that at the bedrock $\left(a_{\max , r}\right)$.

Focusing on the case study, the historic centre area of Baranello is characterized by a geological structure mainly derived from covering tectonics related to the formation of the Apennine chain and sub-Apennine reliefs.

The sedimentary series, variously displaced and dismembered, were poured into the Molise basin causing anomalous overlaps and outcropping of very different units both for facies and for age and paleogeographic genesis.

For the seismic microzonation of this historic centre, data from in-situ surveys were made available by the Municipal Administration of Baranello. Furthermore, in-situ tests were carried out to identify the stratigraphy. Figure 9 shows the areas where the Down-Hole geological characterization tests were carried out. These tests provided the velocity of the propagation of seismic compression and shear waves at different depths.

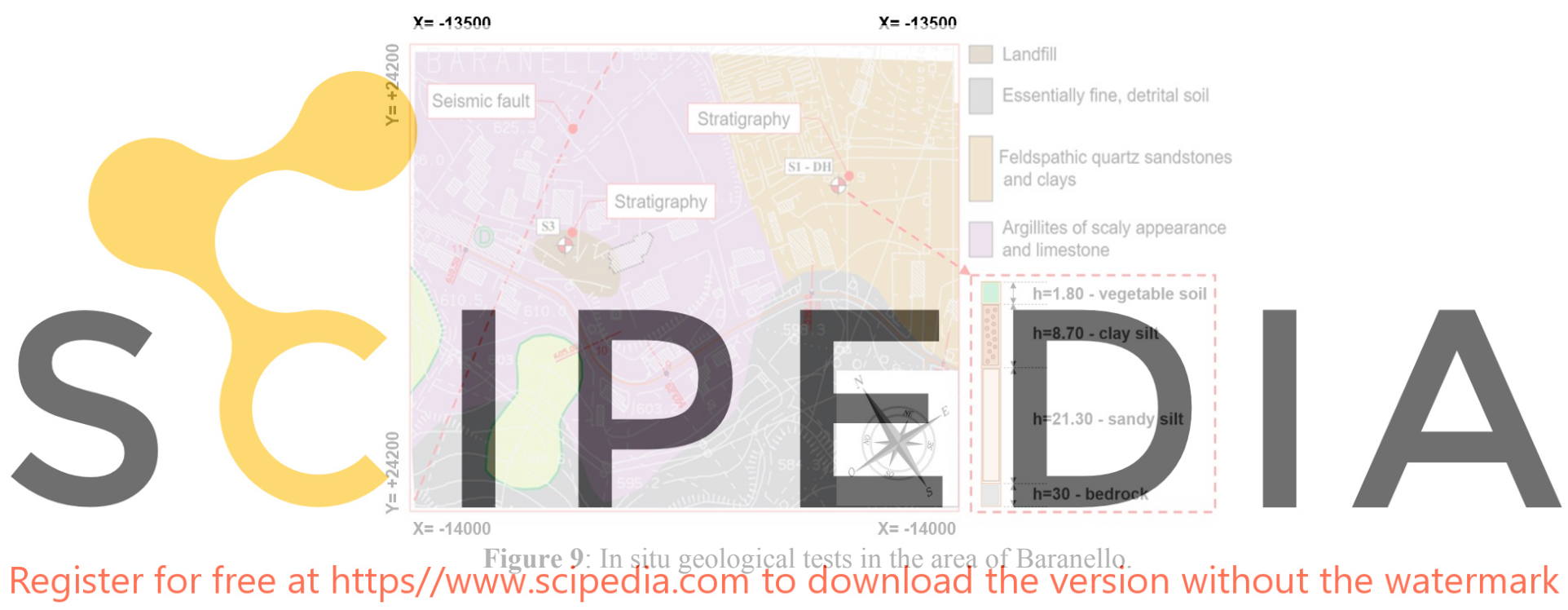

The evaluation of the local amplification coefficient due to soil conditions has been estimated according to a time domain approach, since the main purpose of the work is to characterize the maximum ground amplification deriving from local site effects to correctly predict damage scenarios. Therefore, the accelerogram of the event occurred in Molise in 2002 with epicentre located in Bonefro has been used. The event was characterized by a magnitude, $\mathrm{M}_{\mathrm{w}}$, equal to 6 and a maximum PGA of $0.55 \mathrm{~g}$.

To this purpose, STRATA 1.0 software, developed at the University of Texas, was used for simplified 1D numerical modelling of the geological conditions of seismic motion at bedrock [13].

Thus, based on these considerations, starting from the accelerogram recorded after the Molise earthquake, the accelerogram at the bedrock and the corresponding one amplified on the crustal-surface have been derived (Fig. 10). 


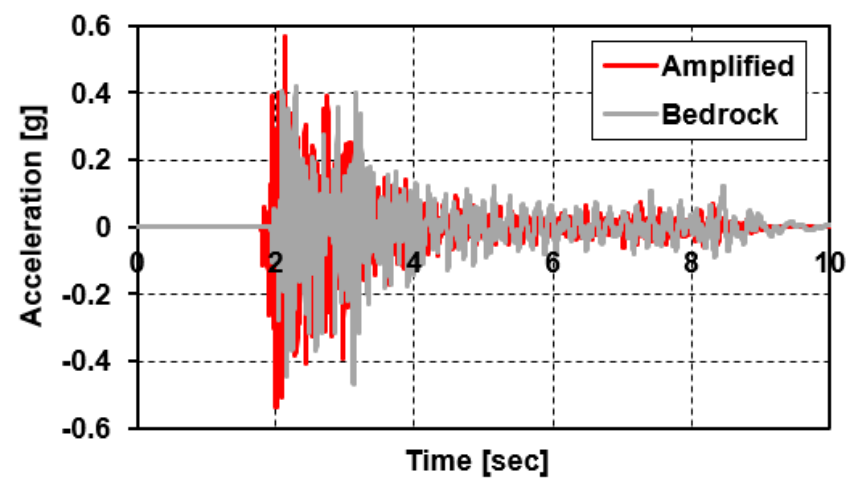

Figure 10: The elaborated accelerograms.

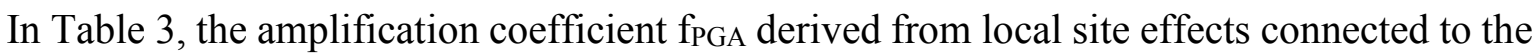
examined ground layers has been proposed.

Table 2: Site amplification factor based on time domain.

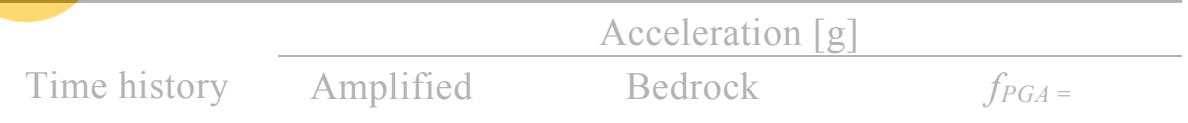

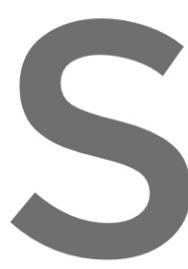

$a_{\max , s} a_{\max , r}$

$\mathrm{a}_{\max , \mathrm{s}} / \mathrm{a}_{\max , \mathrm{r}}$
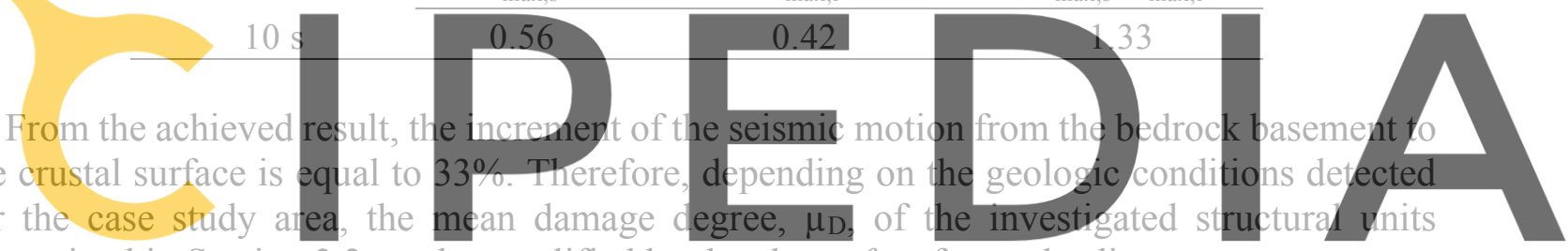

determined in Section 3.2 can be amplified by the above $f_{P G A}$ factor, leading to a more correct

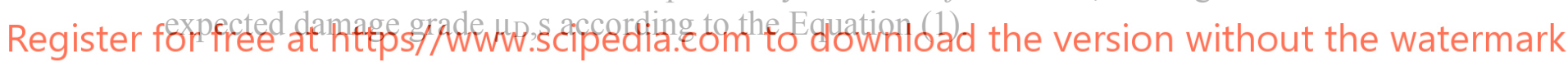

$$
\mu_{\mathrm{D}, \mathrm{s}}=\mu_{\mathrm{D}} \times \mathrm{f}_{\mathrm{PGA}}
$$

Finally, comparing the new damage scenario to that reported in Section 3.2 (Figure 8), it is possible to estimate the damage increase due to site effects, as reported in Figure 11.

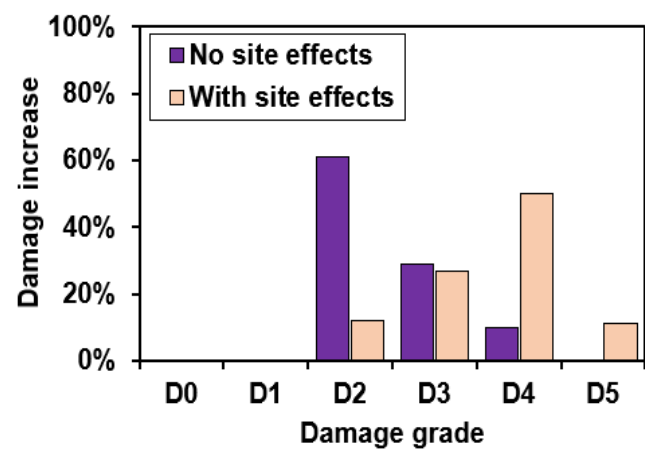

(a) $\mathrm{R}=5 \mathrm{Km} ; \mathrm{M}_{\mathrm{w}}=4$

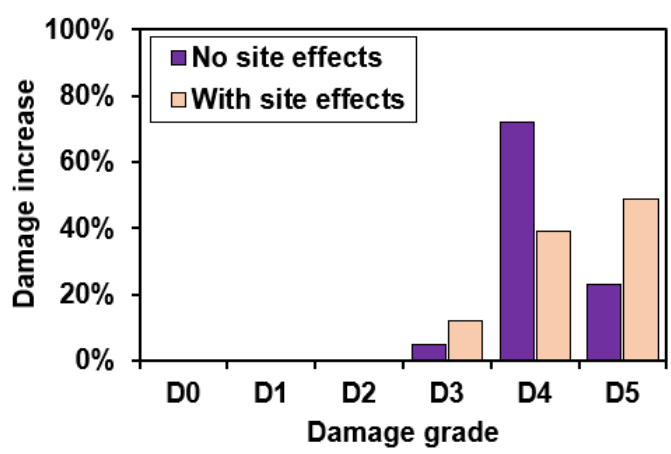

(b) $\mathrm{R}=5 \mathrm{Km} ; \mathrm{M}_{\mathrm{w}}=5$ 


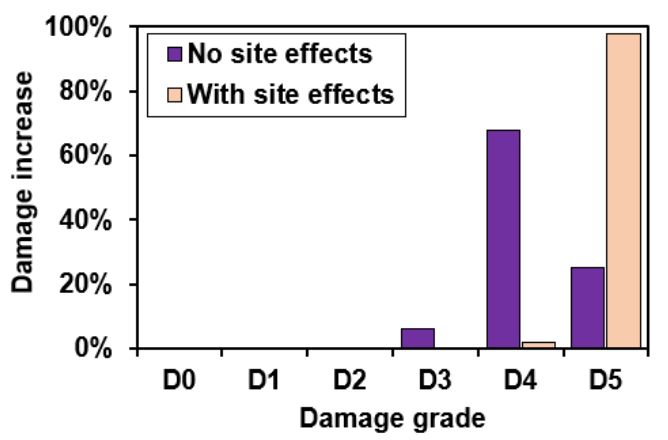

(c) $\mathrm{R}=5 \mathrm{Km} ; \mathrm{M}_{\mathrm{w}}=6$

Figure 11: The influence of local site conditions on the damage scenarios.

\section{CONCLUSIONS}

This study has proposed a simplified methodology to analyse the seismic vulnerability of masonry building aggregates located in historic centres considering the influence of geo-hazard conditions. An urban sector of 300 buildings in the historical centre of Baranello, in the district of Campobasso (Italy), has been identified as study area for the application of the proposed analysis method.

Firstly, the characterisation of the typological classes of the urban sector examined has been done by means of the CARTIS form. From on-site recognition, it has been detected that the prevailing typological class of masonry buildings is the MUR2 (rough-stone) one, which represents $73 \%$ of the building stock examined.

The seismic vulnerability of the inspected urban sector has been estimated through a vulnerability index method conceived for building aggregates. In the urban area, two distinct typological classes, namely A and B, have been identified according to the EMS-98 scale with an expected medium-high vulnerability enclosed in the range [0.4-0.6], while only $30 \%$ of the building sample has a vulnerability index equal to 0.76 . Contrary, for the analysed typological class $\mathrm{B}$, the expected frequency is in the range [0.2-0.4].

Finally, a local seismic amplification factor to consider local site effects has been defined according to the time domain method. Looking at the analysis results, the esteemed amplification factor has been found as equal to 1.33 , which means that the seismic motion increment from the bedrock basement to the crustal surface is equal to $33 \%$. From the new damage scenarios considering local effects, it has been detected a considerable damage increment. In particular, it has been noted that for the epicentre distance of $5 \mathrm{~km}$ and moment magnitude of 4, damage thresholds D2 and D3 have been attained with a damage occurrence probability less than that of the basic case, in which the soil influence has been neglected. Contrary, the D4 and D5 damage levels significantly increase due to the site effects. Instead, considering the worst scenario $\left(R=5 \mathrm{~km}\right.$ and $\left.\mathrm{M}_{\mathrm{w}}=6\right)$, the site effects have reduced drastically the damage levels D3 and D4, but they have increased the D5 threshold with the collapse of $98 \%$ of the buildings in the analysed area.

In conclusion, the proposed work has represented an important starting point for large-scale vulnerability and risk analysis considering site effects, so providing a comprehensive method to predict more precisely damage scenarios into historical centres. 


\section{ACKNOWLEDGEMENTS}

The Authors would like to acknowledge the DPC-ReLUIS 2019-2021 research project for the financial support to the development of the research activity presented in the current paper.

\section{REFERENCES}

[1] Ferreira, T.M., Maio, R.,Vicente, R. Seismic vulnerability assessment of the old city centre of Horta, Azores: calibration and application of a seismic vulnerability index method. Bull. Earthquake Eng. (2017), 15:2879-2899.

[2] Chieffo, N., Formisano, A., Ferreira, T.M. Damage scenario-based approach and retrofitting strategies for seismic risk mitigation: an application to the historical Centre of Sant'Antimo (Italy). Eur. J. Environ. Civ. Eng. (2019).

[3] Chieffo, N., Formisano, A. Geo-hazard-based approach for the estimation of seismic vulnerability and damage scenarios of the old city of senerchia (Avellino, Italy). Geosciences (Switzerland) (2019), 9:1-21.

[4] Morasca, P., Zolezzi, F., Spallarossa, D., Luzi, L. Ground motion models for the Molise region (Southern Italy). Soil Dyn. Earthq. Eng. (2008), 28:198-211.

[5] Cacace, F., Zuccaro, G., De Gregorio, D., Perelli, F.L. Building Inventory at National scale by evaluation of seismic vulnerability classes distribution based on Census data analysis: BINC procedure. Int. J. Disaster Risk Reduct. (2018), 28:384-393.

[6] Formisano, A., Florio, G., Landolfo, R., Mazzolani, F.M. Numerical calibration of an easy method for seismic behaviour assessment on large scale of masonry building aggregates. Adv. Eng. Softw. (2015), 80:116-138.

[7] Formisano, A., Chieffo, N., Mosoarca, M. Seismic Vulnerability and Damage Speedy Estimation of an Urban Sector within the Municipality of San Potito Sannitico (Caserta, Italy). Open Civ. Eng. J. (2018), 11:1106-1121.

[8] Mosoarca M., Onescu I., Azap B.; Onescu E., Chieffo N. Szitar-Sirbu M.; Seismic vulnerability assessment for the historical areas of the Timisoara city, Romania. Eng. Fail. Anal. (2019), 101:86-112.

[9] Onescu I., Mosoarca M., Azap B., Onescu E. Seismic Losses Scenario for Cultural Promenade in Timisoara Capital of Culture 2021, Romania. IOP Conf. Ser.: Mater. Sci. Eng. (2019), 471.

[10] Esteva, D., Harris, D.L. Comparison of pressure and staff wave gage records. Coast. Eng. Proc. (1970), 1, 7.

[11] Locati, M. DBMI15, the 2015 Version of the Italian Macroseismic Database, 2016. Available online: https://emidius.mi.ingv.it (accessed on 02 January 2020) (in Italian).

[12] Chieffo, N., Formisano, A. The influence of geo-hazard effects on the physical vulnerability assessment of the built heritage: An application in a district of Naples. Buildings. (2019), 9.

[13] Flemings, P.B., Grotzinger, J.P., Morris, J.E. Strata: A Stratigraphic Modeling Package, (n.d.). Available online: http://www.jsg.utexas.edu/flemings/intranet/software/strata/strata-download-the-codemanual-and-tutorial/( accessed on 02 January 2020). 